\title{
Erratum to: The association of active smoking with multiple cancers: national census-cancer registry cohorts with quantitative bias analysis
}

Tony Blakely $\cdot$ Jan J. Barendregt $\cdot$ Rachel H. Foster • Sarah Hill · June Atkinson • Diana Sarfati • Richard Edwards

Published online: 22 October 2013

(C) Springer Science+Business Media Dordrecht 2013

Erratum to: Cancer Causes Control (2013)

24:1243-1255

DOI 10.1007/s10552-013-0204-2

Unfortunately, the supplementary Web tables have not been included in the original publication of the article. The complete representations of the tables have been provided in this erratum.

The online version of the original article can be found under doi:10. 1007/s10552-013-0204-2.

Electronic supplementary material The online version of this article (doi:10.1007/s10552-013-0304-z) contains supplementary material, which is available to authorized users.

T. Blakely $(\varangle) \cdot$ R. H. Foster · J. Atkinson · D. Sarfati ·

R. Edwards

Department of Public Health, University of Otago,

PO Box 7343, Wellington, New Zealand

e-mail: tony.blakely@otago.ac.nz

J. J. Barendregt

Centre for Burden of Disease and Cost Effectiveness, School of

Population Health, University of Queensland, Brisbane,

Australia

S. Hill

Social Policy, School of Social and Political Science,

University of Edinburgh, Edinburgh, Scotland, UK 